\title{
Pattern Classification Approaches for Detection of \\ Hypoglycaemia in Type 1 Diabetes
}





\section{Pattern Classification Approaches for Detection of Hypoglycaemia in Type 1 Diabetes}

PhD Thesis by

Morten Hasselstrøm Jensen

Center for Sensory-Motor Interaction, Department of Health Science and Technology, Aalborg University, Denmark

River Publishers

Aalborg 
ISBN 978-87-93102-56-9 (e-book)

Published, sold and distributed by:

River Publishers

Niels Jernes Vej 10

9220 Aalborg Ø

Denmark

Tel.: +45369953197

www.riverpublishers.com

Copyright for this work belongs to the author, River Publishers have the sole right to distribute this work commercially.

All rights reserved (c) 2013 Morten Hasselstrøm Jensen.

No part of this work may be reproduced, stored in a retrieval system, or transmitted in any form or by any means, electronic, mechanical, photocopying, microfilming, recording or otherwise, without prior written permission from the Publisher. 


\section{Acknowledgements}

First and foremost, I would like to express my gratitude to all the people who made it possible for me to work on this very interesting project for two years.

I am very grateful to my main supervisor, Ole Kristian Hejlesen, who helped me immensely with his positive attitude and ability to solve difficult problems. I am also very grateful to my other supervisor, Mette Dencker Johansen, who was always available to guide me in the right direction and to discuss how best to disseminate the results of my research.

I would like to thank Toke Folke Christensen and Lise Tarnow for their help in answering study-related questions and guiding me in the writing of papers. I would also like to thank Edmund Seto, who supervised me during my stay at UC Berkeley. He is a great supervisor and helps me in conducting a valuable study.

My thanks go to all my great colleagues at Aalborg University and UC Berkeley, who were always there to help me when I needed them.

Finally, I would like to thank my family, friends and especially to my wonderful wife, who has supported me throughout the entire process and provided me with ideas, happiness and care. 



\section{Preface}

This PhD dissertation concludes my two years of research at Aalborg University and a three-month period of residence at Berkeley, University of California. The project was funded by the Danish Ministry of Science, Technology and Innovation.

The dissertation focuses on how continuous glucose monitoring can assist people with Type 1 diabetes in their everyday life, despite the reported discouraging inaccuracies. An approach to optimising the precision of continuous glucose monitoring is described, and the possibilities to optimize this approach presented. In addition to this work, an implementation of the approach and the possible challenges are discussed.

The dissertation consists of three parts:

1. An introduction and background, where the background and objectives of the research are described.

2. Four previously published papers presenting possible solutions and challenges.

3. A concluding chapter that discusses the findings and future perspectives. 
PHD THESIS

Morten Hasselstrøm Jensen

\section{List of publications}

The dissertation is based on the following four papers included as chapters.

\section{Paper A}

Jensen MH, Mahmoudi Z, Christensen TF, Tarnow L, Johansen MD, Hejlesen OK. Professional continuous glucose monitoring in subjects with type 1 diabetes: retrospective hypoglycemia detection. Journal of Diabetes Science and Technology 2013; 7(1): 135-43.

\section{Paper B}

Jensen MH, Mahmoudi Z, Christensen TF, Tarnow L, Johansen MD, Seto E, Hejlesen OK. Comparison of retrospective hypoglycemia identification algorithm with a newly developed continuous glucose monitoring calibration algorithm. Journal of Diabetes Technology \& Therapeutics 2013. Submitted.

\section{Paper C}

Jensen MH, Seto E, Christensen TF, Tarnow L, Johansen MD, Hejlesen OK. Real-time hypoglycemia detection in continuous glucose monitoring data from subjects with Type 1 diabetes. Journal of Diabetes Technology \& Therapeutics 2013;15(7).

\section{Paper D}

Jensen MH, Christensen TF, Tarnow L, Johansen MD, Hejlesen OK. An information and communication technology system to detect hypoglycemia in people with Type 1 diabetes. Medlnfo 2013 - The 14th World Congress on Medical and Health Informatics $20^{\text {th }}-23^{\text {th }}$ August 2013. Copenhagen.

Additional scientific contributions of the author related to the above-mentioned work follows:

\section{Conference paper}

Jensen MH, Hua J, Johansen MD, Prakasam G, Hejlesen OK, Seto E. Developing and testing a novel study design for improving hypoglycaemia detection/prediction in continuous glucose monitoring data. SHI $2013-$ Scandinavian Conference on Health Informatics 20 th $A$ ugust 2013. Copenhagen 
Abstract

Jensen MH, Christensen TF, Tarnow L, Johansen MD, Hejlesen OK. Characterization of hypoglycemia by processing subcutaneous sensor and insulin data. 12th Annual Diabetes Technology Meeting 2012. Bethesda.

Paper

Jensen MH, Cichosz SL, Hejlesen OK, Toft E, Nielsen C, Grann O, Dinesen B. Clinical impact of home telmonitoring on COPD patients. Journal of Telemedicine \& e-Health 2012; 18(9); 674-8.

Paper

Jensen MH, Cichosz SL, Dinesen B, Hejlesen OK. Moving prediction of exacerbations in COPD for patients in telehomecare. Journal of Telemedicine and Telecare 2012; 18(2): 99-103.

\section{Conference paper}

Jensen MH, Cichosz SL, Dinesen B, Hejlesen OK. Online prediction of exacerbation in patients with chronic obstructive pulmonary disease using linear discriminant pattern classification. SHI2011 Proceedings: 9th Scandinavian Conference on Health Informatics, 30 August 2011.

\section{Conference Paper}

Heiden S, Buus AA, Jensen MH, Hejlesen OK. A diet management information and communication system to help chronic kidney patients cope with diet restrictions. SHI 2013 - Scandinavian Conference on Health Informatics 20 th August 2013. Copenhagen.

\section{Abstract}

Lilholdt PH, Jensen MH, Hejlesen OK. A Heuristic Evaluation of the telehomecare system from the Danish TeleCare North Large-scale Randomized Trial. SHI 2013 - Scandinavian Conference on Health Informatics $20^{\text {th }}$ August 2013. Copenhagen.

\section{Paper}

Lilholdt PH, Jensen MH, Hejlesen OK. Heuristic Evaluation of a telehealth solution from the Danish TeleCare North Trial. International Journal of Medical Informatics 2013. Submitted. 


\section{PHD THESIS}

Morten Hasselstrøm Jensen

Paper

Mahmoudi Z, Jensen MH, Johansen MD, Christensen TF, Tarnow L, Christiansen JS, Hejlesen OK. Accuracy evaluation of a new real-time continuous glucose monitoring algorithm in hypoglycemia. Journal of Diabetes Technology and Therapeutics 2013. Submitted.

\section{Paper}

Riis HC, Jensen MH, Hejlesen OK. Prediction of exacerbation onsets in chronic obstructive pulmonary disease patients using k-nearest neighbor classification. Journal of Telemedicine and Telecare 2013. Submitted.

\section{Patent}

Jensen MH, Cichosz SL, Dinesen B, Hejlesen OK. Prediction of exacerbations for COPD patients. 7 March 2013. Patent no: PCT/DK2012/050307. IPC: G06F 19/00. 


\section{PHD THESIS}

Morten Hasselstrøm Jensen

\section{Abstract}

Diabetes is a chronic disease that affects 347 million people world-wide. The disease is characterised by insufficient or absent insulin production and secretion and/or insulin resistance, and the consequences are acute and late-diabetic complications. Evidence from the Diabetes Control and Complications Trial suggests that intensive insulin therapy delays the onset and slows the progression of late-diabetic complications. This beneficial effect, however, comes at the expense of an increase in the number of acute hypoglycaemic events, which hampers the therapeutic compliance because people with diabetes are afraid of hypoglycaemia. Measures to detect hypoglycaemia, thereby enabling prevention, would be a possible solution to maintain intensive insulin therapy without increasing the number of hypoglycaemic events. Self-monitoring of blood glucose typically results in 3-4 blood glucose measurements pr. day, which is not enough to detect all hypoglycaemic events. On the other hand, a measurement every 5 minutes with continuous glucose monitoring provides a sufficient amount of information to detect hypoglycaemia. Unfortunately, this technology suffers from inaccuracy, especially in the hypoglycaemic range, due to physiological delay and a delay caused by filter routines. Researchers have for decades worked on the problem of inaccuracy of continuous glucose monitoring, and the devices have improved significantly. Nevertheless, the measuring devices have unacceptable inaccuracies resulting in an unacceptable number of false alerts.

The research described in this thesis utilises pattern classification approaches to optimise the hypoglycaemia detection of continuous glucose monitoring. A large number of features from the continuous glucose monitoring signal and insulin injection were systematically extracted, and then the dimension was reduced with SEPCOR and Forward Selection. Using Support Vector Machines, each continuous glucose monitoring reading was classified as hypoglycaemic or non-hypoglycaemic based on concurrent blood glucose readings. This approach was used to develop a retrospective algorithm and a real-time algorithm using both historic and future data and only historic data, respectively. Both algorithms managed to detect $100 \%$ of the hypoglycaemic events of the dataset, with only one false positive. By comparison, the continuous glucose monitoring device alone detected only $2 / 3$ of the events, but with zero false positives. These results, while promising, should be generalised through training and testing of the algorithms on several datasets, including datasets with spontaneous hypoglycaemic events. 


\section{Abstract in Danish}

Diabetes er en kronisk sygdom karakteriseret ved utilstrækkelig eller manglende insulinproduktion og insulinsekretion og/eller insulinsensitivitet, og konsekvenserne er akutte eller sendiabetiske komplikationer. Evidens fra bl.a. Diabetes Control and Complications Trial viser, at intensiv insulinterapi forsinker start og reducerer progression i komplikationerne. Denne fordelagtige effekt er dog på bekostning af et øget antal akutte hypoglykæmiske episoder, som dermed reducerer terapeutisk compliance fordi patienterne frygter hypoglykæmi. At forebygge hypoglykæmi ved at detektere episoderne vil være en mulig løsning. Fingerstik-monitoring af blodsukker kan typisk kun give 3-4 målinger pr. dag, hvilket ikke er nok til at detektere alle hypoglykæmiske episoder. Derimod kan kontinuer glukosemonitoring give en måling hvert femte minut, hvilket er tilstrækkelig information til at detektere hypoglykæmi. Desværre er teknologien hæftet med unøjagtighed især i hypoglykæmi pga. en fysiologisk forsinkelse og en forsinkelse med relation til de indbyggede filtre. Forskere har i årtier arbejdet med at forbedre nøjagtigheden, hvilket har resulteret i bedre apparater. Apparaterne har dog stadig uacceptable unøjagtigheder, hvilket resulterer i for mange false alarmer.

I arbejdet under denne ph.d. er mønstergenkendelsesprincipper blevet anvendt til at optimere hypoglykæmidetektionen i kontinuerlig glukosemonitorering. Et stort antal features er blevet udtrukket af signalet fra kontinuerlig glukosemonitoring og insulininjektion, hvorefter en feature-reduktion er foretaget vha. SEPCOR og Forward Selection. Ved at bruge Support Vector Machines er hver måling fra kontinuerlig glukosemonitorering blevet klassificeret som hypoglykæmisk eller ikke-hypoglykæmisk baseret på en samtidig blodsukkermåling. Denne tilgang blev brugt til at udvikle en retrospektiv algoritme, der bruger historiske og fremtidige data og en real-time algoritme, der kun bruger historiske data. Begge algoritmer detekterede $100 \%$ af de hypoglykæmiske episoder fra det brugte datasæt med kun én falsk positiv. Til sammenligning detekterede apparatet alene kun 2/3 af episoderne, men med nul falsk positive. Disse resultater er lovende, men skal generaliseres ved at træne og teste algoritmerne på flere datasæt herunder datasæt med spontane hypoglykæmiske episoder. 
PHD THESIS

Morten Hasselstrøm Jensen

\section{Abbreviations}

$\begin{array}{ll}\text { AUC } & \text { Area under the curve } \\ \text { BG } & \text { Blood glucose } \\ \text { CGM } & \text { Continuous glucose monitoring } \\ \text { DCCT } & \text { Diabetes Control and Complications Trial } \\ \text { PG } & \text { Plasma glucose } \\ \text { ROC } & \text { Receiver operating characteristics curve } \\ \text { SMBG } & \text { Self-monitoring of blood glucose } \\ \text { T1D } & \text { Type 1 diabetes } \\ \text { T2D } & \text { Type 2 diabetes } \\ \text { WHO } & \text { World Health Organization }\end{array}$




\section{Table of Content}

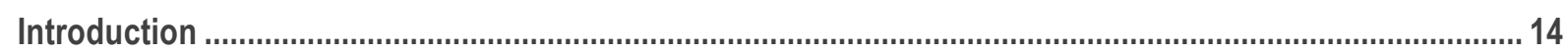

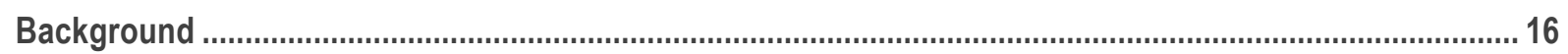

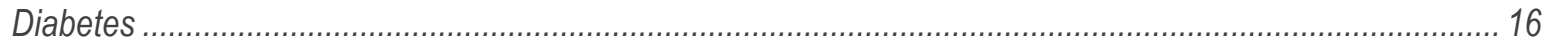

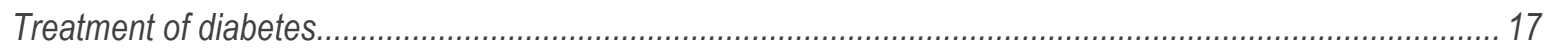

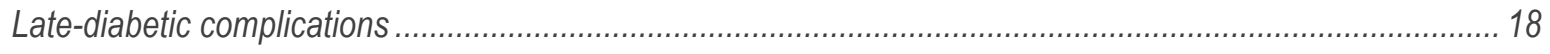

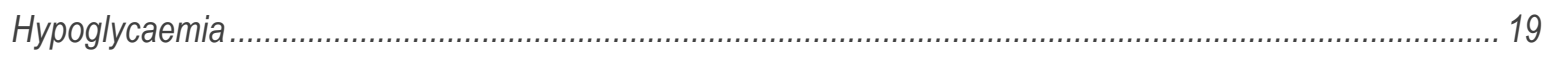

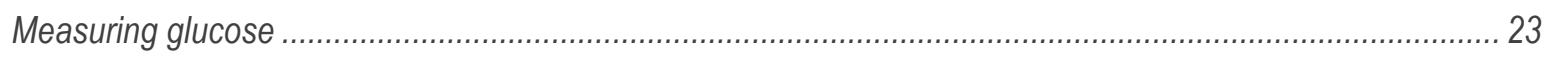

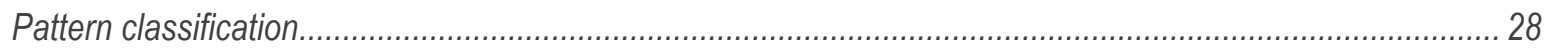

State of the art of continuous glucose monitoring hypoglycaemia identification .............................................. 29

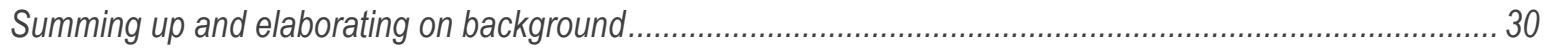

Paper A

Paper B

Paper C

Paper D

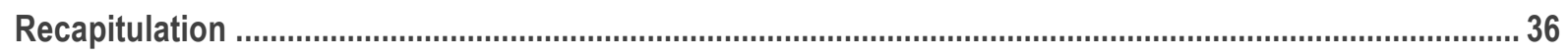

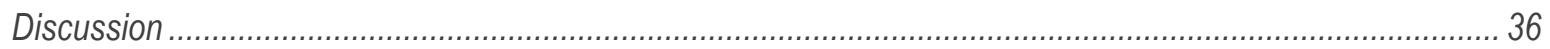

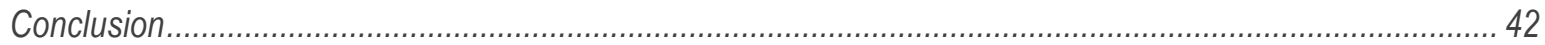

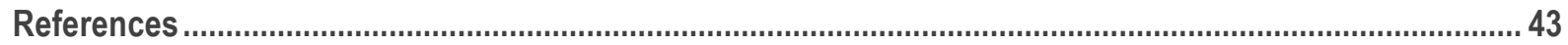


PHD THESIS

Morten Hasselstrøm Jensen

\section{Introduction}

Diabetes is a global disease that affects around 347 million people world-wide [Danaei, 2011]. World Health Organization (WHO) estimated that in 2004, 3.4 million people died from the consequences of fasting high blood glucose (BG) [WHO, 2012]. Diabetes appears in all countries, but the frequency is correlated with living standards. With the increasing level of economic development in countries with high populations, such as India and China, the prevalence of diabetes will explode in the coming decades. About $15 \%$ of all people die with diabetes and $1.5 \%$ die from diabetes, which makes diabetes the $10^{\text {th }}$ most frequent cause of death [Schaffalitzky de Muckadell, 2009]. WHO estimates that in 2030, diabetes will be the $7^{\text {th }}$ most frequent cause of death [WHO, 2011].

Diabetes produces both acute and chronic complications. A possible acute complication is diabetic ketoacidosis, which is a potentially life-threatening condition. The condition develops because a lack of endogenous insulin leads to excessive release of fatty acids, and the by-product from the metabolism of fatty acids is ketone bodies. Diabetic ketoacidosis is responsible for more than 500,000 hospital days per year and a related cost of $\$ 2.4$ billion in the United States [Kitabchi, 2009]. Over time, diabetes may result in several late-diabetic complications involving damage to the heart, blood vessels, eyes, kidneys and nerves: $50 \%$ of people with diabetes die of cardiovascular disease, $1 \%$ of global blindness can be attributed to diabetes, diabetes is among the leading causes of kidney failure, and diabetes increases the risk of foot ulcers, infections and subsequent amputation [Morrish, 2001; WHO, 2012; WHO, 2011]. Treatment of diabetes primarily involves lowering BG, which can be achieved by several measures. In advanced states of diabetes, however, the medicament of insulin might be the primary solution. Aggressive insulin treatment is a successful strategy in delaying the onset and slowing the progression of late-diabetic complications [DCCT, 1993; UKPDS, 1998]. However, the adverse effect, low blood glucose, hypoglycaemia, is a serious obstacle in the implementation of this otherwise successful strategy. If the emergence of hypoglycaemia could be identified, it would be possible to adjust glucose-regulating factors and avoid these debilitating situations.

The technology of continuous glucose monitoring (CGM) contrary to self-monitoring of blood glucose (SMBG), has the potential for hypoglycaemia identification. However, the technology is inaccurate, which complicates its use as a hypoglycaemia detector. Hypoglycaemia models, to optimise the CGM hypoglycaemia prediction rates, have been developed, and especially those models utilising pattern classification approaches have shown promising results [Eren-Oruklu, 2010; Dassau, 2010]. Still, the false alert rates are too high, and the practical usefulness is, thus, unpromising. Typically, the research does not deal with the CGM inaccuracy, and this is one 
of the main issues. This thesis presents how pattern classification approaches can be used to optimise retrospective and real-time CGM hypoglycaemia identification by compensating for the inaccuracy. 
PHD THESIS

Morten Hasselstrøm Jensen

\section{Background}

\section{Diabetes}

Diabetes is a collection of diseases characterised mainly by insufficient or absent insulin production and secretion and/or insulin resistance. Insulin is a hormone that promotes the storage of glucose in muscles, lipid tissues and especially in the liver. Absence of endogenous insulin and/or reduced insulin sensitivity result in abnormally elevated BG, a condition called hyperglycaemia. Hyperglycaemia is a state that can be clinically defined as a fasting condition with BG above $7 \mathrm{mmol} / /$ [Schaffalitzky de Muckadell, 2009]. The threshold of $10 \mathrm{mmol} / \mathrm{l}$, however, is most often used in research [Arabadjief, 2006; Clarke, 2005; Hirsh, 2009; Dassau, 2010]. In this abnormal state, the patient experiences symptoms, such as polyuria, hunger, thirst, fatigue, palpitations, tremor, anxiety, diaphoresis and unintended weight loss. Frequent or persistent episodes of hyperglycaemia are associated with increased risk of developing late-diabetic complications [DCCT, 1993; UKPDS, 1998]. Diabetes can be divided into Type 1 diabetes (T1D) and Type 2 diabetes (T2D) constituting approx. 10\% and $90 \%$ of the 347 million world-wide prevalence, respectively [WHO, 2012]. Another common type is gestational diabetes, which is a condition with a prevalence of $1-14 \%$ in which women without previously diagnosed diabetes during pregnancy are exposed to symptoms resembling T2D both in manifestation and aetiology [Schaffalitzky de Muckadell, 2009; Chasan-Taber, 2011]. Gestational diabetes and other rare types of diabetes will not be discussed further in this thesis.

T1D is defined as diabetes developed due to an autoimmune destruction of the insulin producing pancreatic $\beta$ cells in the Islets of Langerhans. Over the long term, the destruction of the $\beta$-cells results in a complete lack of pancreatic insulin secretion. This not only increases the risk of developing late-diabetic complications, but the resulting hyperglycaemia also leads to the liberation of large quantities of fatty acids, since lipolysis is no longer inhibited by insulin, and the accumulation of the residue acetone of the fatty acids metabolisation, known as ketoacidosis, can be fatal. As a consequence, people with T1D need daily exogenous insulin supply throughout their life to manage glycaemic control. The aetiology of T1D is unknown, but it is thought that viral and chemical compounds could be involved in the pathogenesis. The diagnosis of T1D is confirmed with a venous plasma glucose (PG) measurement random above $11 \mathrm{mmol} / \mathrm{l}$ or fasting above $7 \mathrm{mmol} / \mathrm{l}$.

T2D is defined as diabetes developed due to reduction of insulin sensitivity, which is not fully compensated by increased endogenous insulin secretion. The aetiology of T2D is partly unknown but is related to a modern 
lifestyle characterised by reduced physical activity and increased calorie intake. In Denmark, more than $75 \%$ of people with T2D are pre-obese (BMI $>27 \mathrm{~kg} / \mathrm{m}^{2}$ ) [Schaffalitzky de Muckadell, 2009]. The diagnosis of T2D is confirmed by the same procedure as for T1D. T2D can be distinguished from T1D by levels of above $300 \mathrm{pmol} / \mathrm{I}$ of C-peptide (by-product of insulin production) in a blood sample of the patient.

The research for this thesis has concentrated on T1D, and T2D is not further discussed.

\section{Treatment of diabetes}

Diabetes is a chronic condition, but there are both non-pharmacological and pharmacological therapies available to cope with it. The most important and essential pharmacological therapy used in T1D management is administration of insulin, and the various types of other therapies will not be discussed further in this thesis. Therapy for T1D can be divided into three eras: 1) pre-insulin, 2) insulin, and 3) the era after the Diabetes Control and Complications Trial (DCCT) [Skyler, 2002]. Prior to the introduction of insulin, the diabetes mortality rate approached 100\% within the first two years of diagnosis. After the introduction of insulin in 1922, T1D was no longer an acutely fatal disease, and previously unheard long-term complications began to occur. The consequences of these complications and the desire to prevent or delay them have been the focus of the third era, which was catalysed by the work of the DCCT Research Group. Until the 1980s, insulin was extracted from the pancreas of pigs or cattle. Today, insulin is produced with recombinant DNA technology where insulin genes are placed in the Escherichia Coli bacteria or yeast cells. The resultant analogues encompass various types of fast, intermediate and slow-acting insulin preparations with the goal of mimicking the pulsating pancreatic insulin secretion. Insulin is most often injected in boluses with a pen or syringe or infused continuously with a pump. The site of injection is typically the subcutaneous tissue of the abdomen, thigh or upper arm. The amount of insulin follows a delicate individual tailoring, which has to be weighed against other BG regulating factors such as oral carbohydrate intake and exercise. In the past, the patient passively complied with instructions from the doctor, and the patients who were unable to follow treatment targets were viewed as simply unwilling to follow the instructions. Today, patients are independent and empowered with easy access to disease management information, and the focus in recent decades has thus been on self-care, with support from health professionals. T1D is a disease that requires intensive self-care, as it would be impractical and expensive to visit a physician each day to follow up on management. Although information about management is easily accessible, T1D patients still need huge educational support, especially in the beginning of the disease. Typically, this support consists of a multidisciplinary diabetes team with a physician, a nurse or nutritionist, a social worker and the 


\section{PHD THESIS}

\section{Morten Hasselstrøm Jensen}

general practitioner. In the management process, key targets taken under consideration are [Goldstein, 2003; Holt, 2010]:

- Lowering HbA1c.

- Avoiding hypoglycaemia.

- Prevention, early diagnosis and effective treatment of complications.

- Hypertension treatment.

- Control of other risk factors of cardiac diseases.

- Postprandial targeting.

- Relief of symptoms.

- Minimal injection frequency.

- Minimal patient effort (improve adherence, increase motivation, minimise effort).

For years, the primary output parameter for the glycaemic control has been glycosylated haemoglobin, $\mathrm{HbA1C}$, which indicates the average BG over the past three months. Recommendations suggest that $\mathrm{HbA1c}$ should be lower than $7 \% \sim 53 \mathrm{mmol} / \mathrm{mol} \sim 8.5 \mathrm{mmol} / /$ [ADA, 2010]. The DCCT Research Group [DCCT, 1993] presented conclusive evidence that intensive insulin therapy lowering $\mathrm{HbA} 1 \mathrm{c}$ delays the onset and slows the progression of late-diabetic complications. These conclusions were further strengthened by other similar studies [The Kroc Collaborative Study Group, 1994; Feldt-Rasmussen, 1986; Binchmann-Hansen, 1988; Reichard, 1993; Norwall, 2009]. The DCCT results suggested that if $\mathrm{HbA} 1 \mathrm{C}$ is reduced by $5 \%$, the mean risk for the development of retinopathy would be reduced by $76 \%$ and the risk of progression of retinopathy reduced by $54 \%$. On the other hand, the findings showed that this $\mathrm{HbA} 1 \mathrm{c}$ reduction resulted in more than a three-fold increase in the number of events with hypoglycaemia.

\section{Late-diabetic complications}

Premature mortality among T1D patients continues to be much higher than in the general population even after the successful work of the third era. This is greatly influenced by the presence of late-diabetic complications [Wagner, 2011], such as diabetic nephropathy, retinopathy, neuropathy, arteriosclerosis and the diabetic foot. These complications, as mentioned, occur mainly as a result of frequent or persistent episodes of hyperglycaemia [Norwall, 2009; DCCT, 1993; UKPDS, 1998]. Late-diabetic complications comprise functional 
and structural organ damages due to changes in the vascular system, nerves and connective tissue. The changes can be divided as in table 1.

\begin{tabular}{llll}
\hline \multicolumn{2}{c}{ Vascular changes } & \multicolumn{2}{c}{ Neurological changes } \\
\multicolumn{1}{c}{ Microangiopathy } & Macroangiopathy & Sensomotoric neuropathy & Autonomic neuropathy \\
\hline Capillaries and arterioles & Lower extremity, neck, & Primarily in lower & Blood pressure regulating \\
primarily in kidney & brain and coronary & extremities. & vessels, bladder, intestine \\
glomeruli, retina and & arteries. & & and sexual function. \\
myocardium. & & & \\
\hline
\end{tabular}

Table 1: Categorisation of late-diabetic changes [Schaffalitzky de Muckadell, 2009].

These changes manifest themselves in a variety of comorbidities increasing both morbidity and mortality for the individual, and are very costly for society. For example, cardiovascular disease is one of the leading causes of mortality for people with T1D, and 25 years after diagnosis, one-third of the patients have terminal renal insufficiency [ADA, 1998; Holt, 2010]. The American Diabetes Association has estimated that the total estimated cost of diabetes in 2012 in the United States was \$306 billion [ADA, 2013]. As a consequence, screening of latediabetic complications is an important component in T1D management. The screening should be conducted regularly and at least once a year; it should include a thorough assessment of the patient's need, which demands shared care and teamwork [Holt, 2010].

\section{Hypoglycaemia}

Hypoglycaemia is the most common complication of T1D [DCCT, 1993], and is as much feared as the threat of late-diabetic complications [Pramming, 1991]. In fact, the fear of hypoglycaemia affects the patients to such a degree that they prefer not to follow an intensive insulin therapy [Sanders, 1975]. Factors such as exercise, poisons, alcohol intake, prolonged starvation and organ failure may induce hypoglycaemia, but the most frequent type of hypoglycaemia is iatrogenic hypoglycaemia caused by excessive insulin [Cryer, 2004]. 


\section{PHD THESIS}

Morten Hasselstrøm Jensen

\section{Glucose counterregulation}

The normal human body has a powerful collection of mechanisms to avoid hypoglycaemia, often termed 'the glucose counterregulation'. Decreasing PG triggers a sequence of responses in the healthy human body to counterregulate PG. These responses include: 1) decreased insulin secretion (onset at 4.0-6.0 mmol/l), 2) increased glucagon and epinephrine secretion (onset at 3.6-3.9 mmol/l) and 3) neurogenic and neuroglycopenic symptoms, and cognitive impairments (onset at 2.8-3.0 mmol/l) [Cryer, 2003]. Furthermore, secretion of cortisol and growth hormone is observed after hours of low PG [Frier, 2007; Despopoulos, 2003]. In poorly controlled T1D patients, the glycaemic thresholds shift to higher PG concentrations while they become lower in tightly controlled T1D patients [Boyle, 1988; Amiel, 1988]. In people with T1D, the excessive exogenous insulin supply causes PG to fall lower due to the passive absorption of administered insulin. Therefore, the normal defence mechanism of ceasing insulin secretion is not possible. The next defence mechanism, of increasing glucagon secretion, may also be deficient or completely absent in later stages of T1D. Glucagon is a hormone that mainly antagonises the actions of insulin, but it is suspected that the autoimmune destruction of the $\beta$-cells influences the glucagon producing pancreatic $\alpha$-cells [Fukuda, 1988]. The third defence mechanism, epinephrine, stimulates mobilisation and production of glucose. It also attenuates in T1D, especially as concerns on recent antecedent hypoglycaemia, and it is possibly related to an autonomic failure in the sympathoadrenal response [Dagogo-Jack, 1993]. Although, cortisol and growth hormone have long-term PG restoring effects, the deficient glucose counterregulation entails that T1D patients have 25 times the risk of iatrogenic hypoglycaemia [White, 1983; Bolli, 1984; Despopoulos, 2003]. See figure 1 for an overview of the glucose counterregulation. 


\section{(}

Normal

T1D

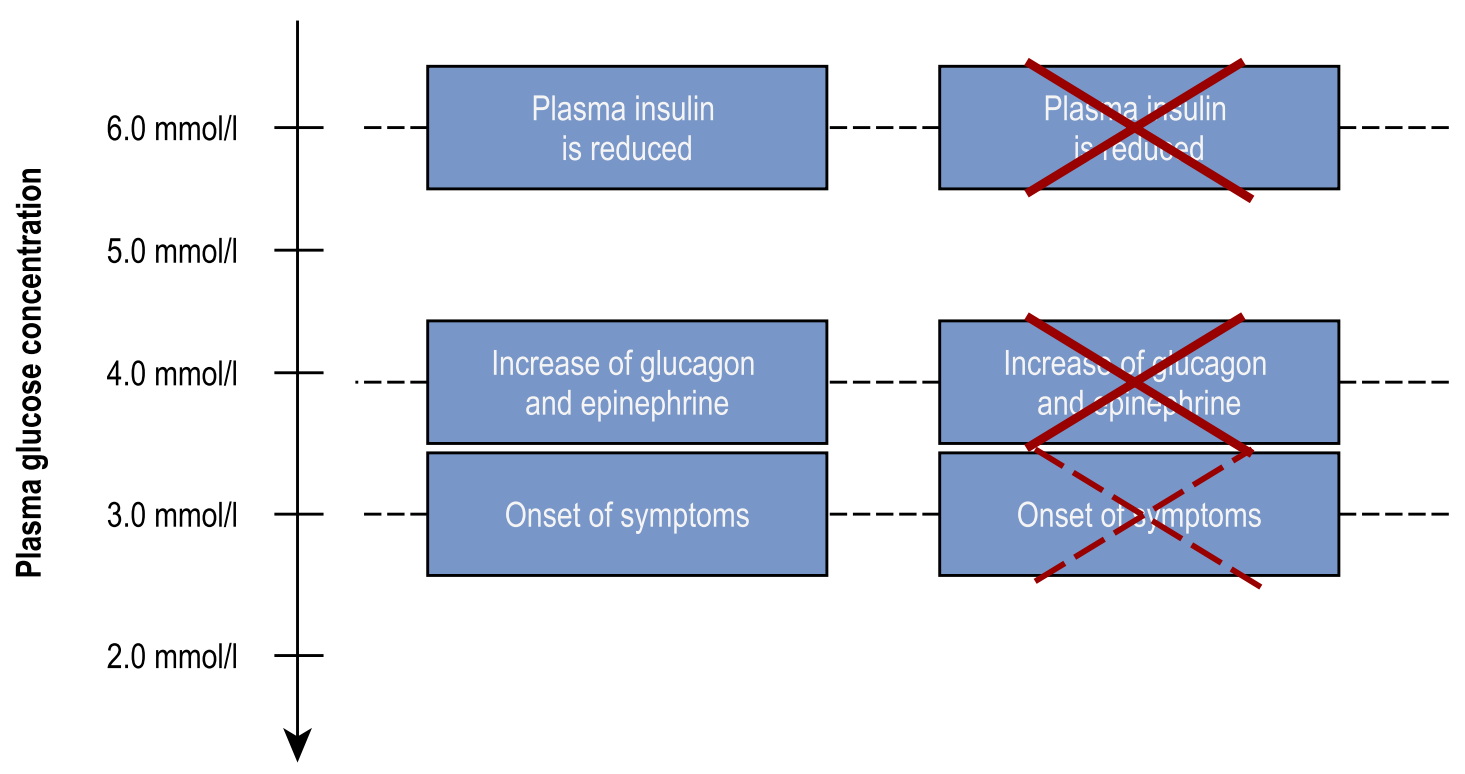

Figure 1: A schematic overview of the glucose counterregulation. Since T1D patients do not produce insulin, they cannot control plasma insulin (when insulin is already administered). Furthermore, glucagon and epinephrine responses tend to be compromised. T1D patients with recurrent hypoglycaemia also lose the ability to feel symptoms.

Attenuation of epinephrine secretion is a marker for an attenuated autonomic sympathetic response that causes the clinical syndrome of hypoglycaemia unawareness, in which hypoglycaemic symptoms are absent [Cryer, 2004]. Hypoglycaemia unawareness is associated with recurrent or persistent severe iatrogenic hypoglycaemia because behavioural defences such as ingestion of carbohydrates are non-existent [Dagogo-Jack, 1993]. The combination of an absent glucagon response and an attenuated epinephrine response causes the clinical syndrome of deficient glucose counterregulation [Cryer, 2002 \& 2003]. Hypoglycaemia-associated autonomic failure is the concept whereby antecedent iatrogenic hypoglycaemia causes both deficient glucose counterregulation and hypoglycaemia unawareness [Cryer, 2004]. Antecedent hypoglycaemia also causes the glycaemic thresholds in the glucose counterregulation to shift to lower PG concentration, which, together with hypoglycaemia-associated autonomic failure, makes antecedent hypoglycaemia a vicious circle. 
PHD THESIS

Morten Hasselstrøm Jensen

\section{Definition of hypoglycaemia}

Researchers on the epidemiology of hypoglycaemia have not employed common definitions with shared specifications, which makes determination of a clear definition challenging [ADA, 2005]. A biochemically defined PG threshold for hypoglycaemia, as proposed by the American Diabetes Association [ADA, 2005] (PG $\leq 3.9$ $\mathrm{mmol} / \mathrm{l})$, is the simplest definition, but due to hypoglycaemia unawareness, triggering of hypoglycaemia-related responses and symptoms shows significant inter-patient variability and even intra-patient variability [ADA, 2005; Cryer, 2004]. Whipple's triad [Whipple, 1938] includes symptoms and is perhaps more appropriate, as shown in table 2.

\section{Whipple's triad}

1. Symptoms consistent with hypoglycaemia.

2. A low PG concentration.

3. Relief of those symptoms when PG is raised.

Table 2: All three criteria in the table should be fulfilled to define hypoglycaemia.

Definitions based on symptomatology have their drawbacks because symptoms vary individually, and many of the symptoms resemble those of comorbidities, resulting in inclusion of false positives. In a study by Pramming et al. [Pramming, 1990] only $29 \%$ of symptomatic hypoglycaemia episodes were accompanied by biochemical evidence. Furthermore, asymptomatic hypoglycaemia is present for T1D patients with hypoglycaemia unawareness. In research practice, information about symptomatology is usually absent, which further, complicates use of Whipple's triad as a definition. Hence, the definition of hypoglycaemia during this research followed that proposed by the American Diabetes Association of $P G \leq 3.9 \mathrm{mmol} / \mathrm{l}$.

\section{Categorisation of hypoglycaemia}

Although, use of symptomatology in hypoglycaemia definition is challenging, as seen above, it is necessary to rely on the use of symptoms in the clinical categorisation of hypoglycaemic episodes. The definition of a severe hypoglycaemic episode of the DCCT Research Group [DCCT, 1997] has gained widespread acceptance, but this 
definition does not consider the degree of neuroglycopenia during the severe hypoglycaemic episode (see table $3)$.

\section{Clinical categorisation of hypoglycaemia}

- Asymptomatic hypoglycaemia. PG $\leq 3.9 \mathrm{mmol} / \mathrm{l}$ and no hypoglycaemia-related symptoms.

- Mild symptomatic hypoglycaemia. PG > $3.9 \mathrm{mmol} / \mathrm{l}$ and hypoglycaemia-related symptoms.

- Severe hypoglycaemia. Assistance from third party needed.

Table 3: Accepted clinical categorisation of hypoglycaemic episodes. 'Profound hypoglycaemia' associated with permanent deficits or even death may be included [Frier, 2007].

This categorisation has advantages in clinical practice, and the definition of severe hypoglycaemia can easily be implemented in research practice. Unfortunately, the definition does not include a biochemical threshold, which may cause problems if information about such events is not accessible from the research studies.

\section{Frequency of hypoglycaemia}

Due to the lack of common definitions, the true frequency of hypoglycaemia remains unclear. Furthermore, many episodes happen at home or in other locations without medical staff, and patients' recall of episodes is generally poor [Frier, 2007]. However, patients in intensive insulin therapy experience asymptomatic hypoglycaemia approx. $10 \%$ of the time ${ }^{1}$, symptomatic hypoglycaemia two times per week and severe hypoglycaemia once a year [DCCT, 1993; Boland, 2001; Gross, 2001; MacLeod, 1993].

\section{Measuring glucose}

From the above description of treatment with insulin and the consequences of hypoglycaemia, it is evident that good glycaemic control is obtained by lowering BG below hyperglycaemia and above hypoglycaemia, i.e. maintaining euglycaemia (figure 2). As concluded previously, intensive insulin therapy reduces $\mathrm{HbA1c}$ at the expense of more hypoglycaemic episodes. Therefore, Cryer's statement that "hypoglycaemia is the limiting factor

\footnotetext{
1 Determined from continuous glucose monitoring.
} 


\section{PHD THESIS}

Morten Hasselstrøm Jensen

in the glycaemic management of diabetes" [Cryer, 2002] may indeed be true. Monitoring BG continuously throughout each day is necessary for people with T1D in order to determine if they should adjust their insulin, carbohydrate intake or exercise to reduce the risk of hypoglycaemia.

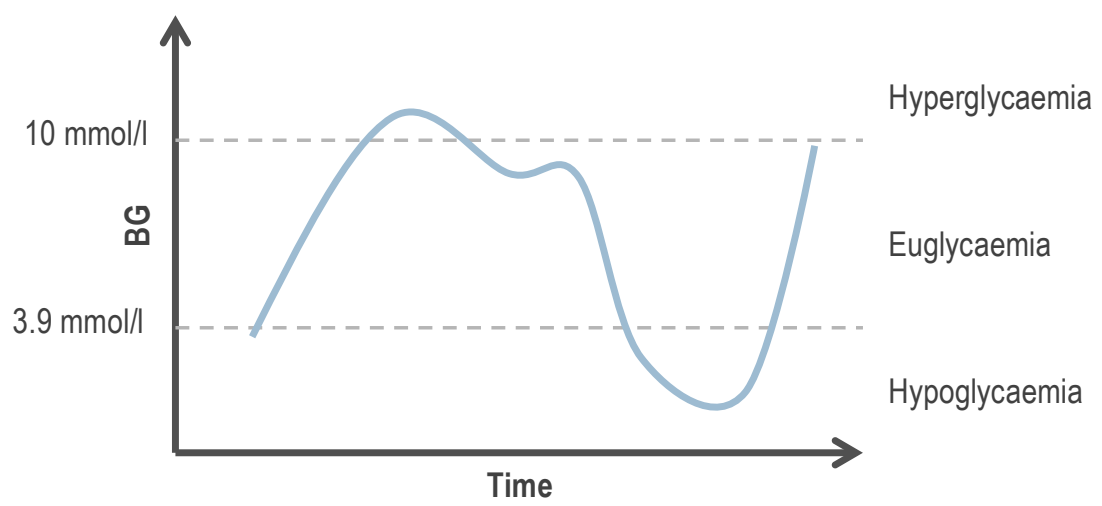

Figure 2: This graph illustrates how BG is continuously varying over time. The art of good glycaemic control is to maintain euglycaemia as much time as possible.

\section{Self-monitoring of blood glucose}

Today, people with T1D most often use self-monitoring of blood glucose (SMBG) with the traditional finger-prick method: 1) the user pricks his/her finger with a disposable lancet, 2) squeezes out a drop of blood, 3) places the capillary blood drop on a test strip, 4) inserts the test strip in a BG meter and 5) reads off the measurement [ADA, 2010]. Figure 3 below shows the different parts of Bayer's new SMBG device, the Contour ${ }^{\circledR}$. Although glucose readings from SMBG in research studies are typically assessed as a reference, examining a patient's BG with several meters generates different BG concentrations [Arabadjief, 2006]. Furthermore, different BG readings are observed from the same BG concentration depending on the user of the meter; for example, a patient or a laboratory clinician. However, modern glucose meters achieve nearly $100 \%$ accuracy compared to blood samples analysed with more sophisticated devices such as the Yellow Springs Instrument STAT [Arabadjief, 2006]. Consequently, throughout the research for this thesis, SMBG was used as a BG reference. Typically, the recommended 3-4 glucose readings with SMBG are collected during the daytime hours and not during night. More measurements per day are unusual due to the inconvenience. This low temporal resolution of BG is a serious disadvantage in avoiding hypoglycaemia. An example of an unfortunate scenario is illustrated in figure 4. 


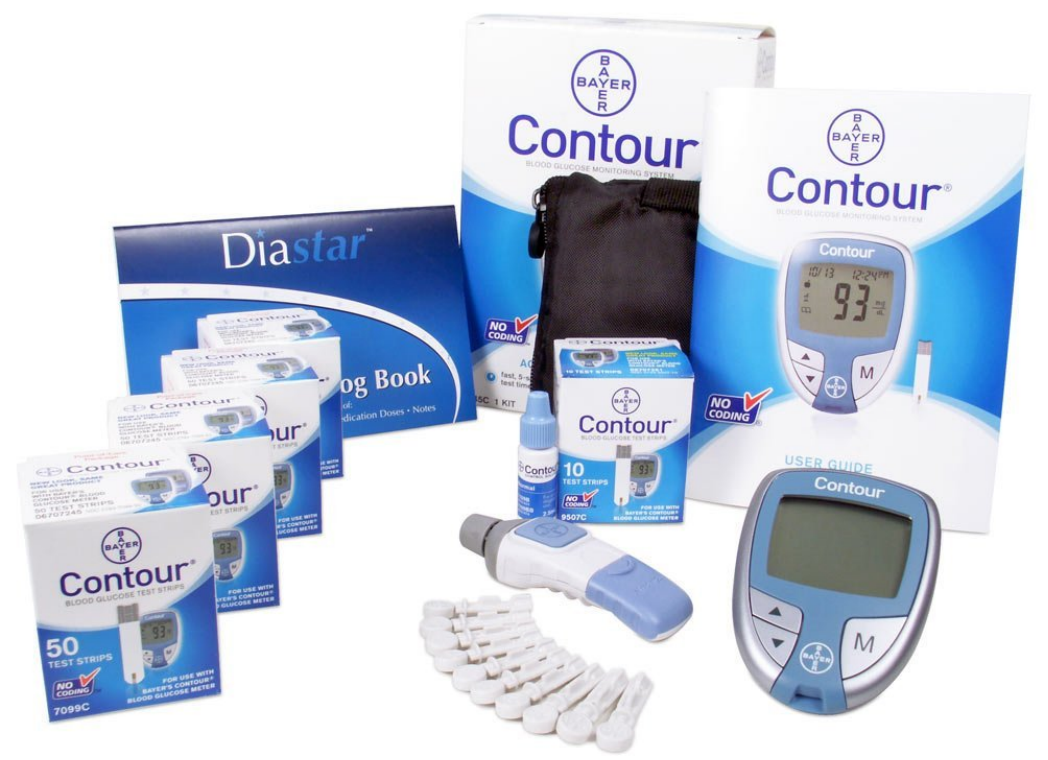

Figure 3: The new SMBG Contour ${ }^{\circledR}$ by Bayer. From left to right: test strips, lancets and lancet-injector, BG meter. [Bayer, 2013]

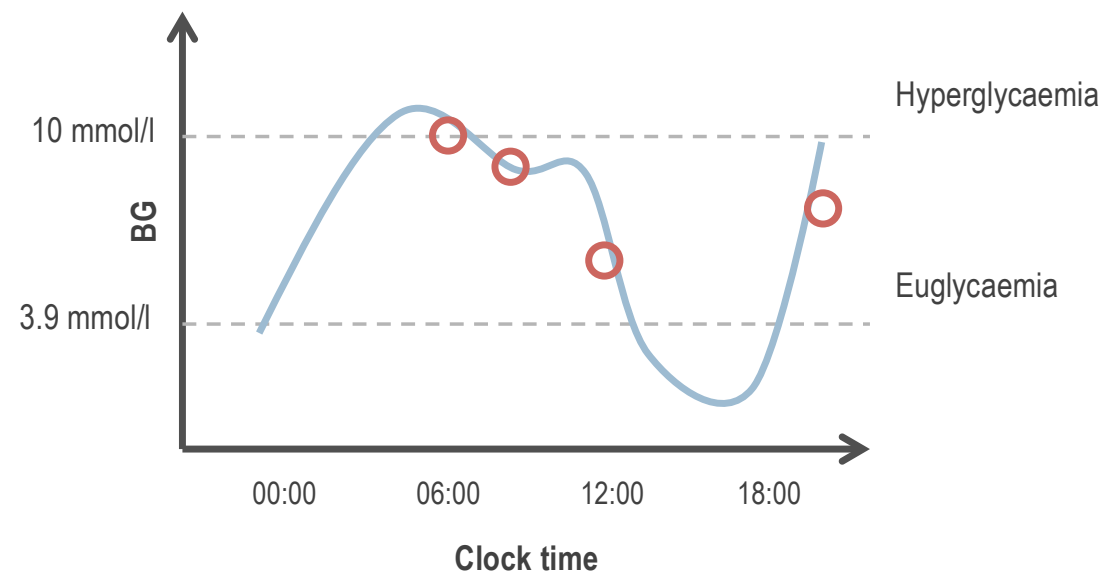

Figure 4: An example of BG monitoring with SMBG (red circles) throughout a day. The hypoglycaemic episode in the afternoon is not revealed due to the low temporal resolution of SMBG. 


\section{PHD THESIS}

Morten Hasselstrøm Jensen

\section{Continuous glucose monitoring}

The fairly new technology of continuous glucose monitoring (CGM) enables the user to obtain much higher temporal resolution than with SMBG. However, CGM cannot replace SMBG, since the CGM devices need to be calibrated 1-5 times per day with SMBG readings. CGM produces a glucose reading every 1-10 minutes by measuring the interstitial glucose in the subcutaneous tissue, typically, of the abdomen. The system consists of 1) a semi-permanent transducer inserted in the subcutaneous tissue for 3-7 days, 2) a transmitter that processes the analogue signal and transmits it, and 3) a device that receives, stores and presents the glucose readings for the user [Wang, 2007]. An example is the Medtronic Pro ${ }^{\mathrm{TM}}$ CGM shown in figure 5. The transducer of the CGM measures glucose in the subcutaneous tissue. This glucose level correlates very well with the level in the blood due to the constant passive diffusion of glucose between these two compartments. However, the diffusion entails a physiological delay of 5-10 minutes, which together with delay from CGM filter routines and calibration issues, causes the CGM glucose readings to be significantly inaccurate compared to SMBG (see figure 6) [Rebrin, 2010; Buckingham, 2006]. This imprecision is especially pronounced in hypoglycaemia. Bode et al. [Bode, 2004] has shown this drawback in a sample-based (CGM-SMBG readings in pairs) sensitivity and specificity of $67 \%$ and $90 \%$, respectively.

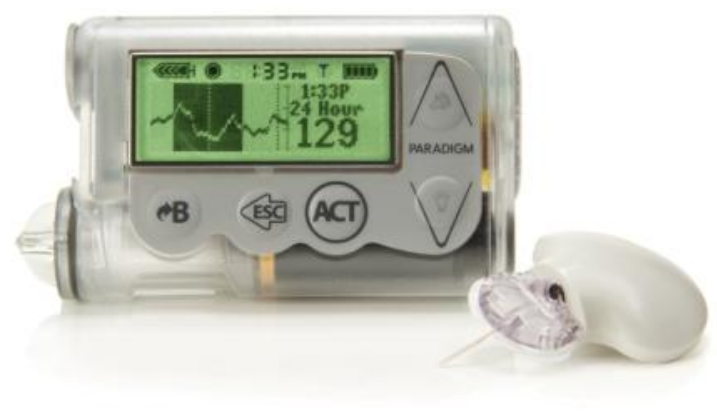

Figure 5: The iPro ${ }^{\mathrm{TM}}$ CGM by Medtronic. The larger device receives, stores and displays readings; the smaller device on the right is the transmitter-transducer. [Medtronic, 2013] 
IG

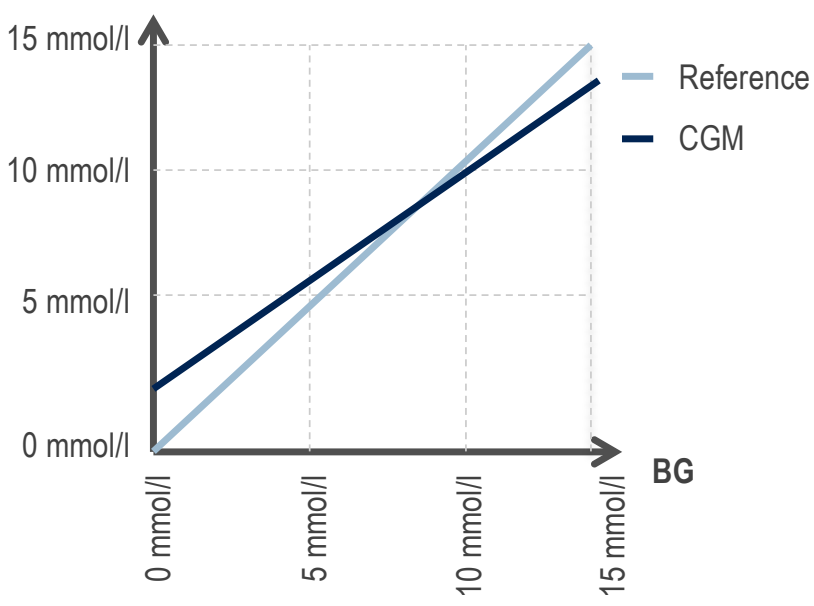

Figure 6: Correlation between CGM output and BG reference. At the calibration point of $8.4 \mathrm{mmol} / \mathrm{l}$, the CGM output is unbiased. At BG values below and above, CGM overestimates and underestimates, respectively. [Rebrin, 2010]

CGM devices were first introduced as a tool administered by professionals to their diabetes patients. Patients had the device attached for 72 hours, and the diabetologist or endocrinologist would then examine the data and discuss any glycaemic control issues with the patient. However, the personal CGM, in which patients wears the device permanently for self-management was quickly introduced. Built-in threshold alarms and even predictive algorithm-based alarms were intended to help the user identify glucose excursions. However, studies [Bode, 2004; Gandrud, 2007] have shown unacceptable false alert rates, ranging from $16-47 \%$, which inhibits the effectiveness of this feature and the use of personal CGM. The high false alert rates seem plausible in light of the previously mentioned CGM inaccuracy. Many researchers [Choleau, 2002; Facchinetti, 2010; Aussedat, 2000; Boyne, 2003; Keenan, 2013] have tried to optimise the calibration of CGM by developing algorithms that linearly model the dynamics between blood and interstitial glucose, but the true underlying dynamics are complex and inaccurate when simplified linearly.

Despite the inaccuracies of the CGM devices, the technology is still promising for the task of improving hypoglycaemia identification. CGM technology has been the main focus of the work in this dissertation. 
PHD THESIS

Morten Hasselstrøm Jensen

\section{Pattern classification}

Use of pattern classification or machine learning to solve biomedical problems has been introduced in recent years. The act of assessing different features about a sample and, based on this assessment, deciding which category the sample belongs to, is a basic task carried out in all medical fields. This use can be further expanded for predicting outcomes in patients' everyday life. For example, it is possible to predict whether a patient with chronic obstructive pulmonary disease will experience an exacerbation in the immediate future by monitoring vital parameters and using these data in a pattern classification model [Jensen, 2012]. In the same way, pattern classification can be used to detect hypoglycaemia. A pattern classification approach consists of a design cycle with the blocks, as illustrated in figure 7 [Duda, 2001].

To develop a pattern classification system, data is necessary. From the data, features can be extracted by 'clever guessing' or by performing more systematic feature extracting. The latter approach tends to end up with a large feature dimension, which must be reduced. Methods such as SEPCOR, Forward/Backward Elimination and Principle Component Analysis are methods that reduce the dimension. Many classification models exist, for example, Linear Discriminant Analysis, Decision Trees, Bayesian Decision Theory, K-nearest Neighbour, Neural Networks and Support Vector Machines. The latter has shown to be most efficient for classification purposes [Meyer, 2003]. When the model has been determined, it has to be trained and evaluated and if the approach does not work, the features or the model may be wrong, and it is necessary to step back in the design cycle. 


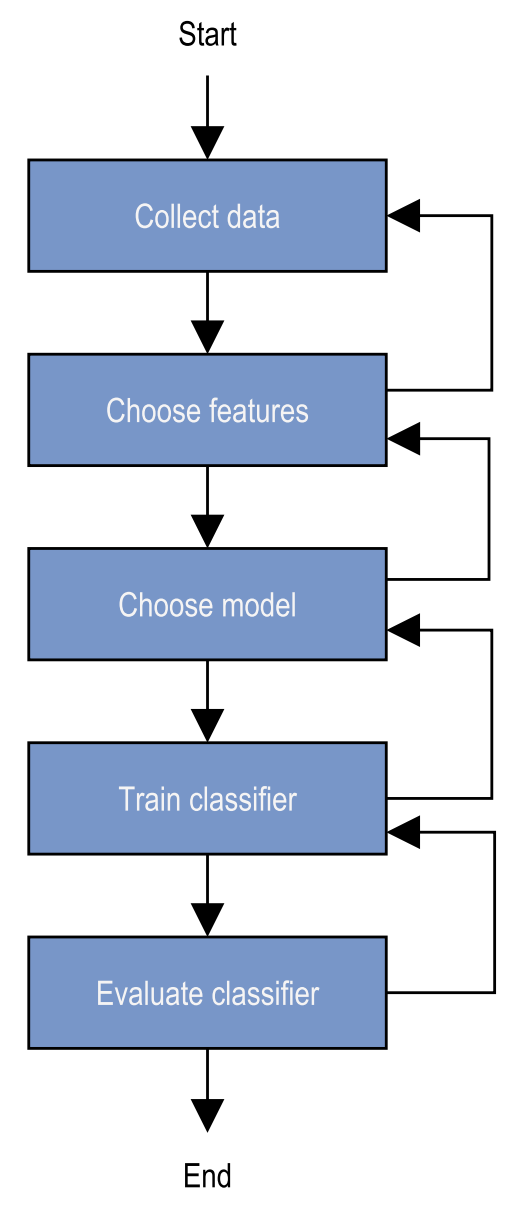

Figure 7: The design cycle of a pattern classification approach. Each block represents a process or step, which is typically taken in iterations. Data must be available to train and test the classifier. From these data, features should be extracted. The extracted features are used in a model, and the model is trained and evaluated. [Duda, 2001]

\section{State of the art of continuous glucose monitoring hypoglycaemia identification}

To optimise CGM hypoglycaemia detection, there are generally two main approaches: 1) optimise the built-in calibration and signal processing algorithms in the CGM devices, or 2) apply intelligent algorithms on the output of the CGM, such as pattern classification algorithms. As mentioned, many researchers have worked with the former approach, but the complexity makes it difficult. Another difficulty that hinders research is the proprietary 


\section{PHD THESIS}

Morten Hasselstrøm Jensen

information within the area. Many companies do not release information about the built-in algorithms, which makes knowledge of steps in the raw interstitial signal-processing missing.

Also, the approach of applying intelligent algorithms on top of the CGM output has some issues. There is a tendency to accept the inaccuracy of the CGM and move to the next step of predicting hypoglycaemia from the CGM data: In a study by Palerm et al. [Palerm, 2007], Kalman filtering was used to predict hypoglycaemia, but only clamp studies with good performance were selected for the analysis. In another study, Pappada et al. [Pappada, 2011] used Neural Networks to predict hypoglycaemia, but with CGM as the reference for time in hypoglycaemia. Also, Perez-Gandia et al. [Perez-Gandia, 2010] used CGM as a reference for time in hypoglycaemia. Sparacino et al. [Sparacino, 2007] discussed the potential of CGM for predicting hypoglycaemia but did not comment on how to deal with the CGM inaccuracy. A common conviction is that devices in the near future will have acceptable levels of precision, which Sparacino and colleagues term as a "general agreement". While this agreement can be accepted here, the data show that in the 40 years of research and development on continuous glucose monitoring systems, the average relative CGM-SMBG difference for DexCom's device, to take one example, has improved significantly but remains 14\% [Gifford, 2013]. This difference indicates that there exists a need for improving the devices immediately to optimise the management of today's patients with T1D. Some researchers incorporated the CGM inaccuracy into their predictive models [Eren-Oruklu, 2010; Cameron, 2008]. However, the majority of the results show unacceptable false alert rates leading to unreliable decision support systems. And the neglect of the CGM inaccuracy leads to too many undetected hypoglycaemic events. Furthermore, focus has been on real-time detection/prediction in personal CGM, but with the high cost, usability problems, training requirements and insurance reimbursement, the focus could be turned to improving retrospective identification in professional CGM as well.

\section{Summing up and elaborating on background}

People with T1D need continuous exogenous insulin supply throughout their life in order to lower their BG. The determination of bolus type, size and time in relation to diet and exercise involves a complex process of tailoring the levels to individual needs, and is determined by the patient with support by his/her physician. Studies have shown that intensive insulin therapy lowers the risk of developing late-diabetic complications. However, the adverse effects in terms of increased number of hypoglycaemic episodes affects the patients to such a degree that they prefer not to follow the intensive regimen. Avoiding these hypoglycaemic events could make the patients follow the intensive regimen, but in order to avoid the events, it is necessary to know when and why they occur so that glucose-regulating factors can be adjusted. Unlike SMBG, CGM technology has the potential to enable the 
patient and the physician to obtain valuable knowledge of the occurrence of the events. Hypoglycaemic inaccuracy, however, necessitates further optimisation of the devices. Traditional modelling approaches, for example those modelling the complex dynamics between the blood and interstitial glucose, seem too difficult to operationalise. Prediction approaches where CGM is assessed as a reference for blood glucose is misleading, because CGM overestimates blood glucose in the hypoglycaemic range, and the prediction models are therefore adjusted to the "wrong" data. A pattern classification approach need not consider the complex dynamics, and such an approach can be used to optimise the CGM hypoglycaemia identification based on blood glucose references rather than the CGM itself as a reference. This leads to the following aim:

The aim of this doctoral research has been to analyse and assess pattern classification approaches for improving identification of hypoglycaemia in CGM data.

During the research project, both retrospective and real-time approaches were tested, evaluated and implemented. These areas were stratified in the following four papers. An optimisation of retrospective hypoglycaemia identification would allow the patient, in collaboration with a physician, to identify when and why the hypoglycaemic events occur and how insulin, carbohydrate intake and exercise can be adjusted to avoid the events. The development of a pattern classification approach to optimise the retrospective hypoglycaemia identification is described in Paper A. For further validation, the approach is compared to a newly developed calibration algorithm, described in Paper B.

The approach is expanded to encompass a configuration in which it is possible to detect hypoglycaemic events in real-time, so that the patient could be warned about hypoglycaemia immediately. The expanded approach is presented in Paper C. Finally, the opportunity to implement the pattern classification in a smart phone and thereby get a better overview of the glucose control and be able to input more data and improve the detection is presented in Paper $\mathbf{D}$. 


\section{Paper A}

\section{Professional continuous glucose monitoring in subjects with type 1 diabetes: retrospective hypoglycemia detection}

Jensen MH, ${ }^{1}$ Mahmoudi Z, ${ }^{1}$ Christensen TF, ${ }^{1}$ Tarnow L, ${ }^{2}$ Johansen MD, ${ }^{1}$ Hejlesen OK, $, 1,34$

1 Department of Health Science and Technology, Aalborg University, Aalborg, Denmark

2 Steno Diabetes Center, Gentofte, Denmark

3 Department of Health and Nursing Science, University of Agder, Grimstad, Norway

${ }^{4}$ Department of Computer Science, University of Tromsoe, Tromsoe, Norway

Published in: Journal of Diabetes Science and Technology 2013. Jan; 7(1): 135-43.

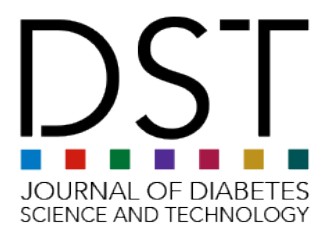




\section{Paper B}

\section{Evaluation of an algorithm for retrospective hypoglycemia detection using professional continuous glucose monitoring data}

Jensen MH, ${ }^{1,2}$ Mahmoudi Z, ${ }^{1}$ Christensen TF, ${ }^{1}$ Tarnow L, ${ }^{3}$ Johansen MD, ${ }^{1}$ Seto E, ${ }^{2,4}$ Hejlesen OK, ${ }^{1,5,6}$

1 Department of Health Science and Technology, Aalborg University, Aalborg, Denmark

2 Center for Information Technology Research In the Interest of Society, UC Berkeley, USA

${ }^{3}$ Steno Diabetes Center, Gentofte, Denmark

${ }^{4}$ School of Public Health, UC Berkeley, USA

${ }^{5}$ Department of Health and Nursing Science, University of Agder, Grimstad, Norway

${ }^{6}$ Department of Computer Science, University of Tromsoe, Tromsoe, Norway

Submitted to: Journal of Diabetes Science and Technology 2013. 


\title{
Paper C
}

\section{Real-time hypoglycemia detection from continuous glucose monitoring data of subjects with Type 1 diabetes}

\author{
Jensen MH, ${ }^{1,2}$ Christensen TF, ${ }^{1}$ Tarnow L, ${ }^{3}$ Seto E, ${ }^{2,4}$ Johansen MD, ${ }^{1}$ Hejlesen OK, $, 1,5,6$ \\ 1 Department of Health Science and Technology, Aalborg University, Aalborg, Denmark \\ ${ }^{2}$ Center for Information Technology Research In the Interest of Society, UC Berkeley, USA \\ ${ }^{3}$ Steno Diabetes Center, Gentofte, Denmark \\ ${ }^{4}$ School of Public Health, UC Berkeley, USA \\ 5 Department of Health and Nursing Science, University of Agder, Grimstad, Norway \\ ${ }^{6}$ Department of Computer Science, University of Tromsoe, Tromsoe, Norway
}

Published in: Journal of Diabetes Technology and Therapeutics 2013; 15(7): 538-43.

Mary Ann Lielest, Inc. \%o publishers 


\section{Paper D}

\section{An information and communication technology system to detect hypoglycemia in people with Type 1 diabetes}

Jensen MH, ${ }^{1}$ Christensen TF, ${ }^{1}$ Tarnow L, ${ }^{2}$ Johansen MD, ${ }^{1}$ Hejlesen OK, $, 3,4$

1 Department of Health Science and Technology, Aalborg University, Aalborg, Denmark

2 Steno Diabetes Center, Gentofte, Denmark

3 Department of Health and Nursing Science, University of Agder, Grimstad, Norway

4 Department of Computer Science, University of Tromsoe, Tromsoe, Norway

Accepted for presented at: The 14th World Congress on Medical and Health Informatics. Copenhagen 2013.

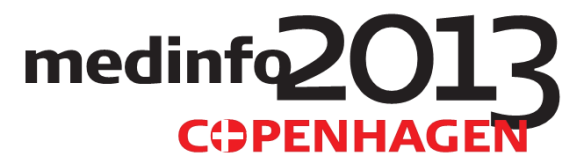


PHD THESIS

Morten Hasselstrøm Jensen

\section{Recapitulation}

Many studies have dealt with optimisation of real-time CGM hypoglycaemia detection. On the other hand, few studies have dealt with the identification of hypoglycaemic events in retrospective CGM data. Yet it is important to have knowledge of historic events in order to adjust glucose-regulating factors and avoid these events in the future. The studies presented in this thesis describe retrospective and prospective pattern classification approaches developed and tested for their ability to detect hypoglycaemia in CGM data. The perspectives of these approaches were explored through the implementation and development of a smartphone application dealing with further patient data recording and visualisation of CGM data and hypoglycaemia warnings.

\section{Discussion}

\section{Dataset}

The CGM used in this study was the Guardian $\mathrm{RT}^{\circledR}$ by Minimed Inc. There exist several other CGM devices, for example, the Freestyle Navigator ${ }^{\circledR}$ by Abbott, which produces a glucose reading every minute. The Navigator device has a slightly lower median absolute relative difference in hypoglycaemia than does the Guardian device [Hirsch, 2009]. Still, the median absolute relative difference is $10.3 \%$, which can be partly explained by the physiological delay, and the device could therefore benefit from the algorithms presented in Paper A and Paper C.

The BG reference of this study was SMBG. The use of SMBG has been hampered because many factors might influence the measurements. In a study by Vesper et al. [Vesper, 2005], the bias was $0.4 \%$ for the HemoCue ${ }^{+}$ glucose meter (as used in this work) compared to a gas chromatography-mass spectrometry reference method when measuring on capillary whole blood. Therefore, the primary factor affecting the measurement is the user, who in the study used in this thesis was an experienced diabetes nurse. Therefore, SMBG is assessed as a valid reference for BG.

When training a binary decision support algorithm it is very important that the sample distribution of the two classes resembles the real-world distribution. From the average hypoglycaemia duration of 47 minutes and the total sampling time of 4.5 days (see Paper $\mathbf{C}$ ), the percentage of time in hypoglycaemia in the case of 17 events would be approx. $12 \%$. For the algorithms to be generalisable to other datasets, this distribution has to reflect the everyday distribution of patients with T1D. From the literature [Boland, 2001; Gross, 2001], it is evident that people with T1D are in hypoglycaemia approx. $10 \%$ of the time during a 24-hour period. The threshold in the literature, however, was $3.3 \mathrm{mmol} / /$ but in all hypoglycaemic events of the study used as a basis for this thesis, 
the BG surpassed $2.5 \mathrm{mmol} / \mathrm{l}$ as a consequence of the protocol. Unfortunately, the frequencies are most often derived from CGM, which generally overestimates glucose in the hypoglycaemic range. Hence, time in hypoglycaemia might be significantly higher. It is not only the distribution of time in hypoglycaemia and nonhypoglycaemia that needs to resemble the real-world distribution. The distribution of CGM-SMBG pairs also needs to resemble the real-world distribution. The frequency of SMBG varied within each session: 'from insulin injection to the end of the hypoglycaemia, blood samples were drawn approx. 10 minutes or more frequently; otherwise every 30-60 minutes'. From this protocol statement, it is evident that the frequency can differ significantly in different periods of the session. For example, it was observed that during glucose decline and nadir, the frequency was much higher than during glucose rise. As a result, the number of BG readings in hypoglycaemia was higher than in non-hypoglycaemia. If only CGM readings concurrent to these BG readings were used in the training of the algorithms, the distribution of CGM readings in hypoglycaemia vs. nonhypoglycaemia would not be $12 \%$ but rather $30-40 \%$, which is not generalizable. For this reason, one SMBG reading for every CGM reading was reconstructed using spline interpolation, which resulted in approximately. $12 \%$ hypoglycaemia CGM readings used in training. In conclusion, time and CGM readings in hypoglycaemia and non-hypoglycaemia are similar to the everyday life of people with Type 1 diabetes, and the developed algorithms might be generalisable.

To test the generalisability of the algorithms, evaluation of additional datasets and datasets with different characteristics are needed. The algorithms were trained and tested on a dataset with insulin-induced hypoglycaemic events, which exhibit a very pronounced rate of declination, a characteristic used in both algorithms in Paper A and Paper C. The ability of the algorithms to optimise the CGM detection of spontaneous hypoglycaemia remains unknown. To have a complete assessment of the algorithms' general potential, it is necessary to test them on data with spontaneous hypoglycaemic events. This is not a trivial task, because it is difficult to obtain a dataset with CGM and such a high frequency of SMBG necessary to correctly identify periods of hypoglycaemia and non-hypoglycaemia. Typically, people measure SMBG 3-4 times per day and in the dataset used here, BG is measured 20-30 times per day, which is highly unusual.

Spline interpolation is an acknowledged method for reconstructing SMBG, but the original frequency of readings needs to be high. In Paper A, a session is presented in which the retrospective algorithm identifies a hypoglycaemic event after 270 minutes marked as a false positive. A closer look could easily convince the observer that a hypoglycaemic event had actually occurred, but this cannot be confirmed due to the infrequent SMBG. This is a clear drawback in using spline interpolation for SMBG reconstruction. The consequence of the interpolation is an incorrectly supervised labelling, which may lower the quality of the evaluation of the algorithms. For example, if the subject experienced a hypoglycaemic event 270 minutes after insulin injection, the result with 


\section{PHD THESIS}

Morten Hasselstrøm Jensen

the current classification would be zero false positives instead of one. A refinement in future work could be to exclude segments with SMBG readings separated by more than 30 minutes.

In the data analysis, hypoglycaemia was defined as an event with BG less than $3.9 \mathrm{mmol} / \mathrm{l}$, but the severity was not categorised. This was done to ensure an objective selection of periods of hypoglycaemia because categorisation implies use of symptomatology, thus introducing an element of subjectivity. Symptomatic-defined hypoglycaemia may have introduced inclusion of false positives. On the other hand, an episode of BG equal to, for example, $3.8 \mathrm{mmol} / \mathrm{l}$ may not have any physiological consequences for some individuals. In this case, one might argue that this should not be considered a hypoglycaemic event. However, BG in this case may be close to counterregulation thresholds, making a detection appropriate. The definition of hypoglycaemia based on Whipple's triad could be used, but episodes of asymptomatic hypoglycaemia occurring among people with hypoglycaemia unawareness are equally important to detect because the possible neurological damages are still present.

In the training and evaluation of the algorithms, time without hypoglycaemia was used as control for the algorithms. This enabled calculation of sample-based specificities, while event-based specificities were impossible to derive. In a study by Eren-Oruklu et al. [Eren-Oruklu, 2010] they had sessions where no hypoglycaemic events occurred. These were defined as 'negative events' and enabled calculation of event-based specificity. This is one way to derive event-based specificity. However, the idea of using the same session as control and hypoglycaemia may make the algorithms more useful in practice because their function is to discriminate between those time intervals where the patient has hypoglycaemic events and those without. Another solution would be to split each session into segments of control and hypoglycaemia and then define each control segment as a negative event. It would be difficult to determine the segment size, and the determination could easily induce bias, because a smaller segment size would increase the number of control events and thereby probably increase the event-based specificities. Consequently, event-based sensitivity together with the number of false positives still seems to be the most unbiased reporting method in terms of its practical utility.

\section{Pattern classification approach}

The applied approach is a combination of methods within pattern classification. The focus was primarily feature extraction, because if information exists in input data to discriminate between periods of hypoglycaemia and periods without, the choice of classification model is less important, which has been realised through experience [Jensen, 2012 \& 2013]. This contradicts traditional pattern classification, where the choice and maybe development of classification model is in focus. Nevertheless, different pattern classification models, such as Decision Trees, Linear Discriminant Analysis, Naive Bayes and Neural Networks were tested but in iterations it 
was observed that Support Vector Machines was always a superior model, which agrees with the literature [Meyer, 2003].

Instead, the main focus was elimination of features. Although SEPCOR has shown good performance, the method has to be utilised with care. Features are correlated, and if the feature that is less discriminative is highly correlated with the feature above, the less discriminative feature is eliminated. This might not be of interest, because the eliminated feature may be able to classify some of the patterns that the superior feature cannot. This was the reason why SEPCOR was used only for a rough elimination. Other methods that combine such features and retain only the discriminative parts of the features could have been utilised, such as Principle Component Analysis [Jolliffe, 2002]. From a research perspective, Principle Component Analysis has the disadvantage that features become arbitrary, meaning that the source of discrimination cannot be identified. For the real-time algorithm, it would have been impossible to know that the feature from the insulin information was not used (under the assumption that nothing from the feature was used), which is inappropriate. In an implementation of the algorithm, the source of discrimination is unimportant, and in this situation, Principle Component Analysis could be used to create the best feature subset and thereby the best algorithm.

\section{Comparison of algorithms}

The two algorithms presented in Paper $\mathbf{A}$ and Paper $\mathbf{C}$ for retrospective and real-time hypoglycaemia detection, respectively, have the same backbone. They extract features from the CGM signal and insulin information, the features are eliminated with SEPCOR and Forward Selection, and the classification model is Support Vector Machines. Features are not extracted in the same interval though. In the algorithm of Paper $\mathbf{A}$, it was possible to review both future as well as historic data $( \pm 2 \mathrm{hr}$ ) so that each CGM reading could be classified, because it should only work retrospectively. The algorithm from Paper $\mathbf{C}$ could not review future data because it had to be real-time. This is the main difference between the two algorithms. Furthermore, in development of the Paper $\mathbf{C}$ algorithm, it was decided to exclude hypoglycaemic events occurring before insulin injection because these were not part of the experimental setup. These two changes explain the incongruence in the area under the receiver operating characteristic curve (ROC-AUC) of the Paper A algorithm (ROC-AUC=0.975) and the Paper C algorithm (ROC-AUC=0.962). Another difference in the results was the use of insulin information: when training Paper $\mathbf{C}$ algorithm, the time interval since the most recent insulin injection was eliminated, and the possible reasons for this elimination are discussed in the paper. When only the parameters of CGM and insulin are entered as input, it is a significant advantage that the insulin feature was eliminated because collection of insulin information become unnecessary when using the Paper $\mathbf{C}$ algorithm in practice. On the implementation side, it would thus be possible to implement the Paper $\mathbf{C}$ algorithm directly in a CGM device. 


\section{PHD THESIS}

Morten Hasselstrøm Jensen

Finally, there was a difference in the event-based evaluation of the algorithms. For the Paper A algorithm, four CGM readings classifying hypoglycaemic with one or more of the readings confirmed by the SMBG were enough to define a true positive. Because the Paper $\mathbf{C}$ algorithm should function in real-time, it was decided that four CGM readings should be classified hypoglycaemic and the fourth would then trigger an alert; if this reading was confirmed by SMBG, it constituted a true positive event. Even though the definition is stricter for the Paper C algorithm, the two algorithms yielded the same event-based result of $100 \%$ sensitivity with one false positive, which is surprising, also because time since last insulin injection was not a feature in the Paper $\mathbf{C}$ algorithm. $\mathrm{A}$ plausible explanation could be that most discriminative information about an imminent hypoglycaemic event can be found in historic CGM data.

\section{Performance of the algorithms}

Sample-based sensitivity of the CGM used in this research was very low, and this has been explained partly by the characteristics of insulin-induced hypoglycaemia (Paper A). However, Zijlstra et al. [Zijlstra, 2013] confirm the low sensitivity even in cases of spontaneous hypoglycaemic events. Compared to the CGM used in a study by Keenan et al. [Keenan, 2010], however, the sensitivity is much lower (31\% vs. $55 \%$ ). In Paper A, we compare the percentage point improvement in sensitivity of the algorithm with the Veo algorithm presented in the study by Keenan et al. The obtained sensitivity with the Veo algorithm is higher, $82 \%$ vs. $78 \%$ with equal specificity of $96 \%$, although the sensitivity improvement of the algorithm presented in Paper A was larger. Hence, the Veo algorithm might be as good or even better than the algorithm presented in Paper A. In an analysis by Kovatchev and Breton [Kovatchev, 2010], they state that the results of the Veo algorithm are based on a retrospective analysis and that the results cannot be anticipated in real-time use. With the real-time algorithm presented in Paper $\mathbf{C}$, we conclude that similar results for the retrospective algorithm in Paper $\mathbf{A}$ can be obtained in real-time.

\section{Implementation of the algorithms}

Paper $\mathbf{D}$ discusses the opportunities to implement the real-time algorithm using a smartphone. The advantage of the smartphone compared to the dedicated devices is visualisation and whether the algorithm's processing of CGM data is carried out on the dedicated devices or on the smartphone is unimportant, although the smartphone's processor is probably much faster. With the current resolutions on smartphone screens, it would be possible to display a very detailed overview of the CGM data. In the current configuration of the algorithm, the only input was CGM data. However, it is anticipated that information about insulin and perhaps meals will need to be included in order to discriminate between periods of spontaneous hypoglycaemia and periods without or for 
prediction purposes. Therefore, the application also inputs information about insulin and carbohydrates, and the user is able to observe this information as bar charts together with the CGM data. This property is very useful for learning about patterns in glucose excursions and leads to the possibility to implement the Paper $\mathbf{A}$ algorithm in the same or in a similar application. If an access point was developed to download patient data from a cloudbased server to a PC in the clinician's office, the patient and the clinician could have easy access to all the necessary data in order to be able to discuss the current diabetes management.

The architecture of the system included access points for the clinician and for the patient's family members, who receive a warning signal every time the patient experiences a hypoglycaemic event. This would probably cause information overload. A suggestion would be to warn only the clinician in case of severe hypoglycaemic events, these being defined biochemically, for example, as BG below 2.5 or $2.0 \mathrm{mmol} / \mathrm{l}$.

Several diabetes management systems have been developed and tested. Cavan et al. [Cavan, 2003] tested a web-based system able of suggesting alternative insulin regimens or meal sizes based on user input of blood glucose, insulin doses and food diary. The system was useful, yet difficulties with data entry hindered its use. In Paper D, the system architecture is presented with wireless transmission of data from the CGM to the smartphone. Using, for example, the Paradigm ${ }^{\circledR}$ REAL-Time Revel ${ }^{\mathrm{TM}}$ System by Minimed Inc., insulin and SMBG readings are transferred as well, leaving only diet for manual registration. Still, registration of diet by estimating carbohydrate content and entering it into the system may be a cumbersome task that leads to data gaps [Cavan, 2003].

\section{Future work}

In Papers A-D, the use of an experimental setup for training and testing the algorithms has been criticised. Similar setups with data from the patients' everyday lives are difficult to obtain because of the high number of SMBG readings needed. However, future work would include design of studies in which this requirement is fulfilled. Such data would reveal if general algorithms to successfully optimise CGM's hypoglycaemia detection are possible, or whether they should be personalised. If the outcome of this investigation is successful, clinical studies, in which the algorithms are implemented, should be performed in order to assess whether the number of hypoglycaemic episodes can be reduced. 
PHD THESIS

Morten Hasselstrøm Jensen

\section{Conclusion}

In this thesis, pattern classification approaches for optimising CGM hypoglycaemia detection have been presented. The performances of the algorithms presented in Paper A and Paper $\mathbf{C}$, with the former validated in Paper B, indicate that it is possible to successfully apply pattern classification approaches within the area of hypoglycaemia detection. Nevertheless, a serious drawback is the development and validation of the algorithms on only a single dataset. Both algorithms need to be trained and validated on several datasets, including spontaneous hypoglycaemia in order to reveal the true clinical benefits. If the performances remain convincing, the algorithms have been prepared to be adapted for existing CGM devices or as presented in Paper D, to be implemented in a smartphone. This enables the user with T1D to use the information in their everyday lives so as to improve their diabetes management by lowering the risk of developing late-diabetic complications while avoiding hypoglycaemia. 


\section{References}

ADA (American Diabetes Association). Consensus development conference on the diagnosis of coronary heart disease in people with diabetes. Diabetes Care. 1998;21(9):1551-9.

ADA (American Diabetes Association). Defining and reporting hypoglycemia in diabetes. Diabetes Care. 2005;28(5):1245-9.

ADA (American Diabetes Association). Standards of medical care in diabetes. Diabetes Care. 2010;33:11-61.

ADA (American Diabetes Association). Summary of revisions for the 2010 clinical practice recommendations. Diabetes Care. 2010;33(1):1-3.

ADA (American Diabetes Association). The economiccCosts of diabetes: is it time for a new treatment paradigm? Diabetes Care. 2013;36(4):775-6.

Amiel S, Sherwin R, Simonson D, Tamborlane W. Effect of intensive insulin therapy on glycemic thresholds for counterregulatory hormone release. Diabetes. 1988;37(7):901-7.

Arabadjief D, Nichols J. Assessing glucose meter accuracy. Curr Med Res Opin. 2006;22(11):2167-74.

Aussedat B, Dupire-Angel D, Gifford R, Klein J, Wilson G, Reach G. Interstitial glucose concentration and glycemia: implications for continuous subcutaneous glucose monitoring. Am J Physiol Endocrinol Metab. 2000;278(4):716-28.

Bayer. Bayer Contour. Available at: http://www.bayercontour.com/. Accessed March 7th, 2013.

Berger M, Rodbard D. Computer simulation of plasma insulin and glucose dynamics after subcutaneous insulin injection. Diabetes Care. $1989 ; 12(10): 725-36$.

Binchmann-Hansen O, Dahl-Jorgensen K, Hanssen K, Sandvik L. The response of diabetic retinopathy to 41 months of multiple insulin injections, insulin pumps and conventional insulin therapy. Arch Ophthalmol. 1988:106(9):1242-6.

Birk H, Moeslund TB. Recognizing gestures from the hand alphabet using principal component analysis. Master's thesis. Aalborg University; 1996.

Blevins TC, Bode BW, Garg SK, Grunberger G, Hirsch IB, JovanovičL, Nardacci E, Orzeck EA, Roberts VL, Tamborlane WV. Statement by the American Association of Clinical Endocrinologists Consensus Panel on continuous glucose monitoring. Endocr Pract. 2010;16(5):730-45. 


\section{PHD THESIS}

\section{Morten Hasselstrøm Jensen}

Blevins TC. Professional continuous glucose monitoring in clinical practice 2010. J Diabetes Sci Technol. 2010;4(2):440-56.

Bode B, Gross K, Rikalo N, Schwartz S, Wahl T, Page C, Gross T, Mastrototaro J. Alarms based on real-time sensor glucose values alert patients to hypo- and hyperglycemia: the guardian continuous monitoring system. Diabetes Technol Ther. 2004;6(2):105-13.

Boland E, Monsod T, Delucia M, Brandt C, Fernando S, Tamborlane W. Limitations of conventional methods of self-monitoring of blood glucose. Diabetes Care. 2001;24(11):1858-62.

Bolli GB, De Feo P, De Cosmo S, Perriello G, Ventura MM, Benedetti MM, Santeusanio F, Gerich JE, Brunetti P. A reliable and reproducible test for adequate glucose counterregulation in type 1 diabetes mellitus. Diabetes. 1984;33(8):732-7.

Boyle P, Schwartz N, Shah S, Clutter W, Cryer P. Plasma glucose concentrations at the onset of hypoglycemic symptoms in patients with poorly controlled diabetes and in nondiabetics. N Engl J Med. 1988;318(23):1487-92.

Boyne M, Silver D, Kaplan J, Saudek C. Timing of changes in interstitial and venous blood glucose measured with a continuous subcutaneous glucose sensor. Diabetes. 2003;52(11):2790-4.

Buckingham BA, Kollman C, Beck R, Kalajian A, Fiallo-Scharer R, Tansey MJ, Fox LA, Wilson DM, Weinzimer SA, Ruedy KJ, Tamborlane WV: Diabetes Research in Children Network Study Group. Evaluation of factors affecting CGMS calibration. Diabetes Technol Ther. 2006;8(3):318-25.

Cameron F, Niemeyer G, Gundy-Burlet K, Buckingham B. Statistical hypoglycemia prediction. J Diabetes Sci Technol. 2008;2(4):612-21.

Cavan D, Everett J, Plougmann S, Hejlesen 0 . Use of the Internet to optimize self-management of type 1 diabetes: preliminary experience with DiasNet. J Telemed Telecare. 2003;9(1):50-2.

Celler BC, Lovell NH, Basilakis J. Using information technology to improve the management of chronic disease. Med J. 2003;179(5): 2426.

Chasan-Taber L. Gestational diabetes: Is it preventable? Am J Lifestyle Med. 2011;6(5):395-406.

Chico A, Vidal-Ríos P, Subirà M, Novials A. The continuous glucose monitoring system is useful for detecting unrecognized hypoglycemias in patients with type 1 and type 2 diabetes but is not better than frequent capillary glucose measurements for improving metabolic control. Diabetes Care. 2003;26(4):1153-7.

Choleau C, Klein J, Reach G, Aussedat B, Demaria-Pesce V, Wilson G. Calibration of a subcutaneous amperometric glucose sensor implanted for 7 days in diabetic patients Part 2. Superiority of the one-point calibration method. Biosens Bioelectron. 2002;17(8):647-54. 
Clarke W. The original Clarke Error Grid Analysis (EGA). Diabetes Technol Ther. 2005;7(5):776-9.

Cryer P, Davis S, Shamoon H. Hypoglycemia in diabetes. Diabetes Care. 2003;26(6):1902-12.

Cryer P. Diverse causes of hypoglycemia-associated autonomic failure in diabetes. N Engl J Med. 2004;350(22):2272-9.

Cryer P. The limiting factor in the glycaemic management of type i and type ii diabetes. Diabetologia. 2002;45(7):937-48.

Cummings E. Patient empowerment and self-efficacy in chronic dsease management: considerations for information systems: development, deployment and evaluation. IRIS 29. 2006.

Dagogo-Jack S, Craft S, Cryer P. Hypoglycemia-associated autonomic failure in insulin-dependent diabetes mellitus. J Clin Invest. 1993:91(3):819-28.

Danaei G, Finucane MM, Lu Y, Singh GM, Cowan MJ, Paciorek CJ, Lin JK, Farzadfar F, Khang Y, Stevens GA, Rao M, Ali MK, Riley LM, Robinson CA, Ezzati M. National, regional, and global trends in fasting plasma glucose and diabetes prevalence since 1980: systematic analysis of health examination surveys and epidemiological studies with 370 country-years and $2 \cdot 7$ million participants. Lancet. 2011;378(9785):31-40.

Dassau E, Cameron F, Lee H, Bequette BW, Zisser H, Jovanovic L, Chase HP, Wilson DM, Buckingham BA, Doyle FJ 3rd. Real-time hypoglycemia prediction suite using continuous glucose monitoring. Diabetes Care. 2010;33(6):1249-54.

DCCT (The Diabetes Control and Complications Trial Research Group). The effect of intensive treatment of diabetes on the development and progression of long-term complications in insulin-dependent diabetes mellitus. N Eng J Med. 1993;329(14):977-86.

DCCT (The Diabetes Control and Complications Trial Research Group). Hypoglycemia in the Diabetes Control and Complications Trial. Diabetes. 1997;46:271-86.

Department for Transport Road Safety Research Group. Report no. 61: stratifying hypoglycemic event risk in insulin-treated diabetes. Department for Transport Road Safety Research; 2006, 68-9.

Despopoulos A, Silbernagl S. Color atlas of physiology. $5^{\text {th }}$ edition. Stuttgart: Georg Thieme Publisher; 2003.

Duda R, Hart P, Stork D. Pattern classification. 2th edition. New York: John Wiley and Sons Inc.; 2001.

El Youssef J, Castle JR, Engle JM, Massoud RG, Ward WK. Continuous glucose monitoring in subjects with Type 1 diabetes: improvement in accuracy by correcting for background current. Diabetes Technol Ther 2010;12(11):921-928. 


\section{PHD THESIS}

\section{Morten Hasselstrøm Jensen}

Ellis SL, Naik RG, Gemperline K, Garg SK. Use of continuous glucose monitoring in patients with type 1 diabetes. Curr Diabetes Rev. 2008;4(3):207-17.

Eren-Oruklu M, Cinar A, Quinn L. Hypoglycemia prediction with subject-specific recursive time-series models. J Diabetes Sci Technol. 2010;4(1):25-33

Facchinetti A, Sparacino G, Cobelli C. Enhanced accuracy of continuous glucose monitoring by online extended kalman filtering. Diabetes Technol Ther. 2010;12(5):353-63.

Feldt-Rasmussen B, Mathiesen E, Deckert T. Effect of two years of strict metabolic control on progression of incipient nephropathy in insulin-dependent diabetes. Lancet. 1986;2(8519):1300-4.

Frier B, Fisher M. Hypoglycaemia in clinical diabetes. 2. ed. Chichester: Wiley; 2007.

Fukuda M, Tanaka A, Tahara Y, Ikegami H, Yamamoto Y, Kumahara Y, Shima K. Correlation between minimal secretory capacity of pancreatic beta-cells and stability of diabetic control. Diabetes. 1988;37(1):81-8.

Gandrud L. The medtronics minimed gold continuous glucose monitoring system: an effective means to discover hypo- and hyperglycemia in children under 7 years of age. Diabetes Technol Ther. 2007;9(4):307-16.

Gifford R. Continuous glucose monitoring: 40 years, what we've learned and what's next. Chemphyschem. 2013. Epub ahead.

Gilliam LK, Hirsch IB. Practical aspects of real-time continuous glucose monitoring. Diabetes Technol Ther. 2009;11(1): 75-82.

Giménez M, Lara M, Jiménez A, Conget I. Glycaemic profile characteristics and frequency of impaired awareness of hypoglycaemia in subjects with T1D and repeated hypoglycaemic events. Acta Diabetol. 2009;46(4):291-3.

Goldstein B, Müller-Wieland D. Textbook of Type 2 diabetes. London: Martin Dunitz Ltd; 2003.

Gross T, Mastrototaro J, Fredrickson L. Detection of unseen hypoglycemia using continuous glucose monitoring. Diabetologia. 2001:A5.

Hirsh I. Realistic expectations and practical use of continuous glucose monitoring for the endocrinologist. $J$ Clin Endocrinol Metab. 2009;94(7):2232-8.

Holt T, Kumar S. Diabetes fra A til Z. Copenhagen: FADL's publisher; 2010.

Jensen M, Cichosz S, Dinesen B, Hejlesen O. Moving prediction of exacerbation in chronic obstructive pulmonary disease for patients in telecare. J Telemed Telecare. 2012;18(2):99-103. 
Jensen MH, Christensen TF, Tarnow L, Mahmoudi Z, Johansen MD, Hejlesen OK: Professional continuous glucose monitoring in subjects with type 1 diabetes: retrospective hypoglycemia detection. J Diabetes Sci Technol. 2013;7(1):135-143.

Jolliffe I. Principal component analysis. 2nd edition ed. Heidelberg: Springer verlag; 2002.

Jungheim K, Wientjes KJ, Heinemann L, Lodwig V, Koschinsky T, Schoonen AJ; Glucose Monitoring Study Group. Subcutaneous contiryous glucose monitoring: feasibility of a new microdialysis-based glucose sensor system. Diabetes Care. 2001;24(9):1696-7.

Kaufman FR, Gibson LC, Halvorson M, Carpenter S, Fisher LK, Pitukcheewanont P. A pilot study of the continuous glucose monitoring system: clinical decisions and glycemic control after its use in pediatric type 1 diabetic subjects. Diabetes Care. 2001;24(12):2030-4.

Keenan D, Cartaya R, Mastrototaro J. Accuracy of a new real-time continuous glucose monitoring algorithm. J Diabetes Sci Technol. 2010;4(1):111-8

Keenan D, Mastrototaroa J, Weinzimerb S, Steilc G. Interstitial fluid glucose time-lag correction for real-time continuous glucose monitoring. Biomed Signal Process Control. 2013;8(1):81-9.

King C, Anderson SM, Breton M, Clarke WL, Kovatchev BP. Modeling of calibration effectiveness and blood-to-interstitial glucose dynamics as potential confounders of the accuracy of continuous glucose sensors during hyperinsulinemic clamp. J Diabetes Sci Technol. 2007;1(3):317-22.

Kitabchi A, Miles J, Umpierrez G, Fisher J. Hyperglycemic crises in adult patients with diabetes. Diabetes Care. 2009;32(7):1335-43.

Koller D, Sahami M. Toward optimal feature selection. International Conference on Machine Learning. 1996, 284-92.

Kovatchev B, Anderson S, Heinemann L, Clarke W. Comparison of the numerical and clinical accuracy of four continuous glucose monitors. Diabetes Care. 2008;31(6):1160-4.

Kovatchev B, Breton M. The accuracy of a new real-time continuous glucose monitoring algorithm: an analysis. J Diabetes Sci Technol. 2010;4(1):119-22.

MacLeod K, Hepburn D, Frier B. Frequency and morbidity of severe hypoglycaemia in insulin-treated diabetic patients. Diabetes Medicine. 1993;10(3):238-45.

Mahmoudi Z, Johansen MD, Christiansen JS, Hejlesen OK. A novel algorithm for processing and calibration of continuous clucose monitoring data. Diabetes Technol Ther. 2013. Accepted for publication. 


\section{PHD THESIS}

\section{Morten Hasselstrøm Jensen}

Mahmoudi Z, Johansen MD, Christiansen JS, Hejlesen OK. A novel algorithm for processing and calibrating continuous glucose monitoring data. 12th Annual Diabetes Technology Meeting. Bethesda, MD, USA. Diabetes Technology Society. 2012.

Medtronic. Medtronic Diabetes. Available at: http://www.medtronicdiabetes.com/. Accessed March 8th, 2013.

Meyer D, Leisch F, Hornik K. The support vector machine under test. Neurocomputing. 2003;55(1):169-86.

Morrish N, Wang S, Stevens L, Fuller J, Keen H. Mortality and causes of death in the WHO Multinational Study of Vascular Disease in Diabetes. Diabetologia. 2001;44(2):14-21.

Murphy HR, Rayman G, Lewis K, Kelly S, Johal B, Duffield K, Fowler D, Campbell PJ, Temple RC. Effectiveness of continuous glucose monitoring in pregnant women with diabetes: randomised clinical trial. BMJ. 2008;337:a1680.

Nardacci EA, Bode BW, Hirsch IB. Individualizing care for the many: the evolving role of professional continuous glucose monitoring systems in clinical practice. Diabetes Educ. 2010;36(1):4-21.

Norwall M, Arnqvist H, Bojestig M, Ludvigsson J. Good glycemic control remains crucial in prevention of late diabetic complications - the Linköping Diabetes Complications Study. Pediatr Diabetes. 2009;10(3):168-76.

Nuryani N, Ling SS, Nguyen HT. Electrocardiographic signals and swarm-based support vector machine for hypoglycemia detection. Ann Biomed Eng. 2012;40(4):934-45.

Palerm C, Bequette B. Hypoglycemia detection and prediction using continuous glucose monitoring - a study on hypoglycemic clamp data. J Diabetes Sci Technol. 2007;1(5):624-9.

Pappada SM, Cameron BD, Rosman PM, Bourey RE, Papadimos TJ, Olorunto W, Borst MJ. Neural Network-based real-time prediction of glucose in patients with insulin-dependent diabetes. Diabetes Technol Ther. 2011;13(2):135-41.

Pedersen-Bjergaard U, Pramming S, Thorsteinsson B. Recall of severe hypoglycaemia and self-estimated state of awareness in type 1 diabetes. Diabetes Metab Res Rev. 2003;19(3):232-40.

Pérez-Gandia C, Facchinetti A, Sparacino G, Cobelli C, Gómez EJ, Rigla M, de Leiva A, Hernando ME. Artificial Neural Network algorithm for online glucose prediction from continuous glucose monitoring. Diabetes Technol Ther. 2010;12(1):81-8.

Pramming S, Thorsteinsson B, Bendtson I, Binder C. Symptomatic hypoglycaemia in 411 type 1 diabetic patients. Diabetic Medicine. 1991;8(3):217-22. 
Pramming S, Thorsteinsson B, Bendtson I, Binder C. The relationship between symptomatic and biochemical hypoglycaemia in insulindependent diabetic patients. J Intern Med. 1990;228(6):641-6.

Rebrin K, Sheppard N, Steil G. Use of subcutaneous interstitial fluid glucose to estimate blood glucose: revisiting delay and sensor offset. J Diabetes Sci Technol. 2010;4(5):1087-98.

Reichard P, Nilsson B, Rosenqvist U. The effect of long-term insulin treatment on the development of microvascular complications of diabetes mellitus. N Engl J Med. 1993;329(5):304-9.

Sanders K, Mills J, Martin F, Horne D. Emotional attitudes in adult insulin-dependent diabetics. J Psychosom Res. 1975;19(4):241-6.

Schaffalitzky de Muckadell O, Haunsoe S, Vilstrup H. Medicinsk kompendium. 17. ed. Copenhagen: Nyt Nordisk Forlag; 2009.

Skyler J. Atlas of diabetes. 2 edition ed. Philadelphia: Current Medicine; 2002.

Sparacino G, Zanderigo F, Corazza S, Maran A, Facchinetti A, Cobelli C. Glucose Concentration can be predicted ahead in time from continuous glucose monitoring sensor time-series. IEEE Trans Biomed Eng. 2007;54(5):931-7.

The Kroc Collaborative Study Group. Blood glucose control and the evolution of diabetic retinopathy and albuminuria. N Engl J Med. 1994;311(6):365-72.

UKPDS (UK Prospective Diabetes Study Group). Intensive blood-glucose control with sulphonylureas or insulin compared with conventional treatment and risk of complications in patients with type 2 diabetes. Lancet. 1998:352(9131):837-53.

Vesper H, Archibold E, Myers G. Assessement of trueness of glucose measurement instruments with different specimen matrices. Clinica Chimica Acta. 2005;358(1-2):68-74.

Wagner D. Type 1 diabetes complications. Rijeka: InTech; 2011.

Wang J. Electrochemical glucose biosensors. American Chemical Society. 2007;108(2):814-25.

Weber KK, Lohmann T, Busch K, Donati-Hirsch I, Riel R. High frequency of unrecognized hypoglycaemias in patients with type 2 diabetes is discovered by continuous glucose monitoring. Exp Clin Endocrinol Diabetes. 2007;115(8):491-4.

Whipple A. The surgical therapy of hyperinsulinism. J Int Chir. 1938:237-76.

White N, Skor D, Cryer P, Levan doski L, Bier D, Santiago J. Identification of type 1 diabetic patients at increased risk for hypoglycemia during intensive therapy. N Eng J Med. 1983;308(9):485-91. 


\section{PHD THESIS}

\section{Morten Hasselstrøm Jensen}

WHO (World Health Organization). Fact sheet n³12. Diabetes. September 2012.

WHO (World Health Organization). Global data on visual impairments 2010. Geneva: World Health Organization; 2012.

WHO (World Health Organization). Global status report on noncommunicable diseases 2010. Geneva: World Health Organization; 2011.

Wojciechowski P, Ryś P, Lipowska A, Gaweska M, Małecki M. Efficacy and safety comparison of continuous glucose monitoring and selfmonitoring of blood glucose in type 1 diabetes: systematic review and meta-analysis. Pol Arch Med Wewn. 2011;121(10):333-43.

Zijstra E, Heise T, Nosek L, Heinemann L, Heckermann S. Continuous glucose monitoring: quality of hypoglycaemia detection. Diabetes Obes Metab. 2013;15(2):130-5. 
A part of this thesis has been removed from this publication due to copyright. 